\title{
Ultraviolet optical absorptions of semiconducting copper phosphate glasses
}

\author{
Byeong-Soo Bae and Michael C. Weinberg \\ Arizona Materials Laboratories, Department of Materials Science and Engineering, University of Arizona, \\ Tucson, Arizona 85712
}

(Received 23 November 1992; accepted for publication 22 February 1993)

\begin{abstract}
Ultraviolet optical absorptions of semiconducting copper phosphate glasses with batch compositions of $40 \%, 50 \%$, and $55 \% \mathrm{CuO}$ have been examined as a function of $\left[\mathrm{Cu}^{2+}\right] /\left[\mathrm{Cu}_{\text {total }}\right]$ in the glasses. The optical energy gap, $E_{\text {opt }}$, obtained from the fundamental absorption edge depends upon both glass composition and the ratio $\left[\mathrm{Cu}^{2+}\right] /\left[\mathrm{Cu}_{\text {total }}\right]$ in the glass. $E_{\text {opt }}$ increases as $\mathrm{CuO}$ content and $\left[\mathrm{Cu}^{2+}\right] /\left[\mathrm{Cu}_{\text {total }}\right]$ in the glass are raised. This trend is explained by speculating upon the energy band structure of copper phosphate glass. However, the Urbach energy, $\Delta E$, obtained from the tail of the optical absorption edge is affected solely by $\left[\mathrm{Cu}^{2+}\right]$ $\left[\mathrm{Cu}_{\text {total }}\right]$ in the glass. An absorption band of $\mathrm{Cu}^{1+}$ (in its crystal field) occurs in the vicinity of the absorption tail and is responsible for the increase of $\Delta E$ with reducing $\left[\mathrm{Cu}^{2+}\right] /\left[\mathrm{Cu}_{\text {total }}\right]$ in the glass.
\end{abstract}

\section{INTRODUCTION}

Phosphatc glasses containing transition metal oxides are of interest due to their semiconducting properties. ${ }^{1-8}$ The electronic conduction in these glasses occurs by polaron transfer from a lower to a higher valence state transition metal ion. Copper phosphate based glasses show some interesting behavior, and thus the electrical and optical properties of these glasses have been studied extensively. ${ }^{9-23}$ It has been reported that copper phosphate glass exhibits mixed conduction phenomena in which ionic conduction as well as electronic conduction occurs in the glass. ${ }^{9}$ Also, copper calcium phosphate glasses have showed electrical switching phenomena. ${ }^{10,22,23}$

Copper phosphate glasses exhibit an optical absorption band in the visible-near infrared region and a fundamental optical absorption edge in the ultraviolet (UV) region. It is well known that $\mathrm{Cu}^{2+}$ in glass exhibits an optical absorption band in the visible region and creates color in the glass. ${ }^{24}$ This optical absorption band arises from transitions associated with the internal transitions between $d$-orbital electrons of $\mathrm{Cu}^{2+}$ and the absorption band positions in crystalline and amorphous hosts have been described by the use of ligand field theory. ${ }^{25}$ On the other hand, the origin of the fundamental optical absorption edge in the UV region for the glasses containing copper is not clear. For other transition metal oxide containing glasses, it has been argued that the UV absorption edge originates from an electron transition between oxygen $2 p$ and transition metal ion $3 d$ states. ${ }^{26,27}$

The UV optical absorption edges of copper phosphatebased glasses containing other oxides have been studied by Hogarth and co-workers. ${ }^{16-21}$ They found that the absorption edge varies with the glass composition. This variation was explained as resulting from the change of the ratio of $\mathrm{Cu}^{1+}$ and $\mathrm{Cu}^{2+}$ in the glasses of different composition. ${ }^{16,18,20}$ In other words, they observed that the more $\mathrm{CuO}$ replaced by glass modifiers such as $\mathrm{Na}_{2} \mathrm{O}, \mathrm{BaO}$, and $\mathrm{CaO}$ in the copper phosphate glasses, the higher the
$\left[\mathrm{Cu}^{2+}\right] /\left[\mathrm{Cu}_{\text {total }}\right]$ became. Also, they found that the optical energy gap increased as the latter ratio grew. However, in a separate study, they also controlled the $\left[\mathrm{Cu}^{2+}\right] /\left[\mathrm{Cu}_{\text {total }}\right]$ ratio by adding iodine as an oxidizing agent to the same copper calcium phosphate glass composition ${ }^{17}$ and found that the optical energy gap diminished with the reduction of the $\left[\mathrm{Cu}^{1+}\right] /\left[\mathrm{Cu}^{2+}\right]$ ratio. This finding is in contradiction with the interpretation that the optical energy gap is controlled solely by the valence states ratio of copper. Thus, it appears that both the glass composition and the copper valence states ratio change the optical absorption edge. However, systematic studies of the dependence of the fundamental optical absorption edge of copper phosphate glass upon the copper valence states ratio (for identical base composition) have not been reported.

In addition to the fundamental optical absorption edge, amorphous semiconductors are characterized by an exponential tail that occurs in the low-energy part of the absorption edge and is called the Urbach tail. ${ }^{28-30}$ The Urbach tail has been shown to vary with change in glass composition, which produces change in copper valence states ratio of the glasses. ${ }^{19-21}$ It would be of interest to investigate whether glass composition or copper valence states ratio in glass has a greater influence upon the Urbach tail. In addition to the intrinsic UV absorption edge, absorption bands of $\mathrm{Cu}^{1+}$ have been observed in the UV region of the spectra of phosphate glasses. ${ }^{31-35}$ These absorption bands may occur in the region of the absorption edge and thus alter the shape and position of the Urbach tail.

The present study addresses several of the issues mentioned above. Namely, a quantitative investigation of the change in these optical parameters is performed in which the $\left[\mathrm{Cu}^{2+}\right]$ ratio $\left(\left[\mathrm{Cu}^{2+}\right] /\left[\mathrm{Cu}_{\text {total }}\right]\right)$ and the glass composition are changed independently in simple binary copper phosphate glasses. The $\left[\mathrm{Cu}^{2+}\right]$ ratio in the glass is controlled without changing the glass composition (or adding reducing or oxidizing agents) by using various melting times, as was done previously. ${ }^{36}$ 
TABLE I. Preparations and optical properties of glasses.

\begin{tabular}{|c|c|c|c|c|c|c|c|}
\hline Sample & $\begin{array}{c}\text { Batch } \\
\text { composition }\end{array}$ & Crucible & $\begin{array}{l}\text { Melting } \\
\text { temperature }\end{array}$ & $\begin{array}{l}\text { Melting } \\
\text { time }\end{array}$ & $\frac{\left[\mathrm{Cu}^{2+}\right]}{\left[\mathrm{Cu}_{\text {total }}\right]}(\%)$ & $\begin{array}{l}\text { Urbach energy } \\
\qquad(\Delta E)\end{array}$ & $\begin{array}{l}\text { Optical energy } \\
\text { gap }\left(E_{\text {opt }}\right)\end{array}$ \\
\hline $\mathbf{A}$ & \multirow[t]{5}{*}{$50 \mathrm{CuO} .50 \mathrm{P}_{2} \mathrm{O}_{5}$} & \multirow[t]{5}{*}{ quartz } & $1000^{\circ} \mathrm{C}$ & $15 \mathrm{~min}$ & $22.3 \pm 5.6$ & 0.82 & 4.39 \\
\hline $\mathrm{B}$ & & & $1000^{\circ} \mathrm{C}$ & $30 \mathrm{~min}$ & $50.5 \pm 3.6$ & 0.55 & 4.29 \\
\hline c & & & $1000^{\circ} \mathrm{C}$ & $1 \mathrm{~h}$ & $74.0 \pm 2.8$ & 0.40 & 4.21 \\
\hline D & & & $1000{ }^{\circ} \mathrm{C}$ & $2 \mathrm{~h}$ & $92.1 \pm 1.9$ & 0.32 & 4.16 \\
\hline $\mathrm{E}$ & & & $1000^{\circ} \mathrm{C}$ & $6 \mathrm{~h}$ & $99.5 \pm 1.0$ & 0.28 & 4.14 \\
\hline$F$ & \multirow[t]{2}{*}{$40 \mathrm{CuO} .60 \mathrm{P}_{2} \mathrm{O}_{5}$} & \multirow[t]{2}{*}{ quartz } & $1000^{\circ} \mathrm{C}$ & $30 \mathrm{~min}$ & $48.6 \pm 4.3$ & 0.51 & 4.62 \\
\hline $\mathbf{G}$ & & & $1000^{\circ} \mathrm{C}$ & $6 \mathrm{~h}$ & $99.8 \pm 0.8$ & 0.26 & 4.37 \\
\hline $\mathbf{H}$ & \multirow[t]{2}{*}{$55 \mathrm{CuO} .45 \mathrm{P}, \mathrm{O}_{5}$} & \multirow[t]{2}{*}{ quartz } & $1100^{\circ} \mathrm{C}$ & $30 \mathrm{~min}$ & $56.3 \pm 3.6$ & 0.48 & 4.10 \\
\hline I & & & $1100^{\circ} \mathrm{C}$ & $6 \mathrm{~h}$ & $82.3 \pm 2.8$ & 0.36 & 4.06 \\
\hline $\mathrm{J}$ & \multirow[t]{2}{*}{$50 \mathrm{CuO} .50 \mathrm{P}_{2} \mathrm{O}_{5}$} & quartz & $1200^{\circ} \mathrm{C}$ & $6 \mathrm{~h}$ & $97.2 \pm 1.7$ & 0.31 & 4.15 \\
\hline $\mathrm{K}$ & & Alumina & $1200^{\circ} \mathrm{C}$ & $6 \mathrm{~h}$ & $89.5 \pm 2.5$ & 0.33 & 4.04 \\
\hline
\end{tabular}

\section{EXPERIMENTAL PROCEDURE}

CuO- $\mathrm{P}_{2} \mathrm{O}_{5}$ glasses having compositions 40,50 , and 55 mol \% $\mathrm{CuO}$, were prepared using analytical reagent grades of chemicals, $\mathrm{CuO}$ and $\mathrm{NH}_{4} \mathrm{H}_{2} \mathrm{PO}_{4}$. About $60 \mathrm{~g}$ of chemicals were mixed with isopropyl alcohol and dried to obtain homogenized batches. A quartz crucible $(100 \mathrm{ml}$ capacities) containing the batch was initially heated at $500{ }^{\circ} \mathrm{C}$ for about $2 \mathrm{~h}$ in order to evaporate ammonia and water in the batch and minimize the tendency of subsequent phosphate loss. A quartz crucible was used since it was found that a quartz crucible was more inert to melt copper phosphate glass than an alumina crucible. ${ }^{36}$ The crucible was transferred to another furnace, which was preheated at the melting temperature, $1000^{\circ} \mathrm{C}$. The batch was melted in air from $15 \mathrm{~min}$ to $6 \mathrm{~h}$, depending on the desired valence states ratio of copper in the glass. A small portion of the melt was collected on the end of a quartz tube and then blown into a glass film. The thicknesses of the blown films were measured with the aid of an optical microscope and a photo scale reticle. The films were 4-6 $\mu \mathrm{m}$ thick. For the purpose of chemical analyses, bulk samples were prepared by pouring the melt onto a clean copper plate. All prepared samples were stored in a vacuum desiccator to prevent moisture attack.

All samples were confirmed to be amorphous by $x$-ray diffraction and to be homogeneous by optical microscopy and scanning electron microscopy (SEM). IR spectroscopy was used to ascertain that the hydroxyl content of the blown films and bulk samples was relatively small. The concentrations of the total copper and $\mathrm{Cu}^{2+}$ in the bulk glasses were determined using complexometric titration described previously. ${ }^{36}$ It was assumed that the concentrations of the blown films and bulk samples were identical. The optical absorption measurements were made in the wavelength range of $200-500 \mathrm{~nm}$ for the thin blown films, using a Shimadzu UV-3100 UV-VIS-NIR Recording Spectrophotometer.

\section{UV OPTICAL ABSORPTION SPECTRA}

The compositions, melting conditions and $\left[\mathrm{Cu}^{2+}\right] \mathrm{ra}$ tios of the glasses that were prepared are given in Table I.
The actual compositions of the glasses may differ somewhat from the nominal composition due to vaporization of phosphorous, and this departure is larger for lower $\mathrm{CuO}$ content in glasses, as illustrated in previous work. ${ }^{36}$

\section{A. Effect of valence states of copper}

Optical absorption spectra of the glasses with $50 \%$ $\mathrm{CuO}$ batch composition having various $\left[\mathrm{Cu}^{2+}\right]$ ratios are shown in Fig. 1. There are no sharp absorption edges, which is characteristic of most amorphous materials. The absorption edge shifts to shorter wavelength as the $\left[\mathrm{Cu}^{2+}\right]$ ratio decreases. However, for a smallcr $\left[\mathrm{Cu}^{2+}\right]$ ratio, the change in the slope of the absorption curve is relatively smaller so that the UV cutoff is less abrupt.

\section{B. Effect of composition}

Figure 2 presents the optical absorption spectra of the reduced ( $F$ and $H$ ) and oxidized ( $G$ and $I$ ) glasses of $40 \%$ $\mathrm{CuO}$ and $55 \% \mathrm{CuO}$ batch composition glasses, respectively. The absorption edges of the reduced glasses occur at shorter wavelengths and the tails of the absorption edge of the reduced glasses are longer than those of the oxidized glasses for each composition, as observed for the $50 \% \mathrm{CuO}$

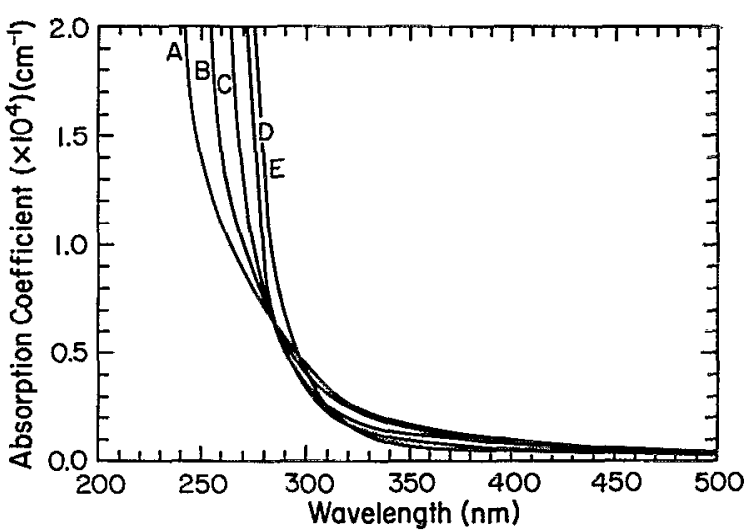

FIG. 1. Optical absorption spectra of glasses with $50 \% \mathrm{CuO}$ batch composition having various $\left[\mathrm{Cu}^{2+}\right]$ ratios. 


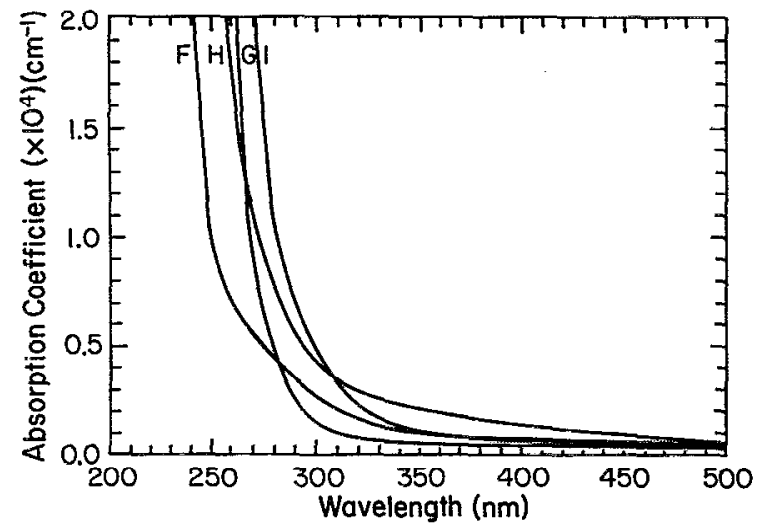

FIG. 2. Optical absorption spectra of oxidized and reduced glasses with $40 \%$ and $55 \%$ CuO batch composition.

batch composition. Also, one observes that the UV cutoff moves to shorter wavelength as the CuO content of the glass is reduced. The spectra of Figs. 1 and 2 clearly illustrate that UV cutoff is a function of both $\mathrm{CuO}$ content and $\left[\mathrm{Cu}^{2+}\right]$ ratio in the glasses.

\section{DISCUSSION}

\section{A. Optical absorption edge}

In the high absorption portion of the UV absorption edge, the absorption coefficient $\alpha(\omega)$ for amorphous semiconductors is found to obey the relation suggested by Davis and Mott: ${ }^{28}$

$$
\alpha(\omega) \hbar \omega=B\left(\hbar \omega-E_{\text {opt }}\right)^{n},
$$

where $B$ is constant, $\hbar \omega$ is the photon energy, and $E_{\text {opt }}$ is optical energy gap. Mott and Davis ${ }^{29}$ proposed that most amorphous semiconductors have allowed direct transitions and $n$ in Eq. (1) is 2, as also proposed by Tauc ${ }^{37}$ under the assumption of parabolic bands. Also, for many copper phosphate glasses it has been shown that Eq. (1) with $n=2$ fits the experimental results very well. ${ }^{16-21}$ The optical energy gap, $E_{\text {opt }}$, may be identified with a pseudogap between localized and extended states, ${ }^{28,29}$ or localized states in the valence and conduction bands. ${ }^{37}$ These values are obtained from Eq. (1) by extrapolation of the linear parts of the $(\alpha \hbar \omega)^{1 / 2}$ vs $\hbar \omega$ curves to $(\alpha \hbar \omega)^{1 / 2}=0$.

Figure 3 illustrates $(\alpha \hbar \omega)^{1 / 2}$ vs $\hbar \omega$ curves in the range of $\alpha(\omega)>10^{4} \mathrm{~cm}^{-1}$ for glasses having different $\left[\mathrm{Cu}^{2+}\right] \mathrm{ra}-$ tios and 50\% CuO batch composition [Fig. 3(a)], and $40 \%$ and $55 \% \mathrm{CuO}$ batch compositions [Fig. 3(b)]. The curves show linear portions where Eq. (1) is obeyed, and the linear region is greater and exhibits larger slope as the $\left[\mathrm{Cu}^{2+}\right]$ ratio grows. The $E_{\text {opt }}$ values obtained from Fig. 3 vary from 4.06 to $4.62 \mathrm{eV}$ and are listed in Table I. For $50 \% \mathrm{CuO}$ batch composition, $E_{\text {opt }}$ decreases from 4.39 to $4.14 \mathrm{eV}$ as $\left[\mathrm{Cu}^{2+}\right]$ ratio is increased. This trend is also present in the $40 \% \mathrm{CuO}$ and $55 \% \mathrm{CuO}$ batch compositions. These values are higher than those that have been obtained by Horgarth and co-workers $\left(3.42^{18}\right.$ and 3.24 $\mathrm{eV}^{19}$ for $50 \mathrm{CuO} 50 \mathrm{P}_{2} \mathrm{O}_{5}, 3.62 \mathrm{eV}^{20}$ for $35 \mathrm{CuO} 65 \mathrm{P}_{2} \mathrm{O}_{5}$ ).

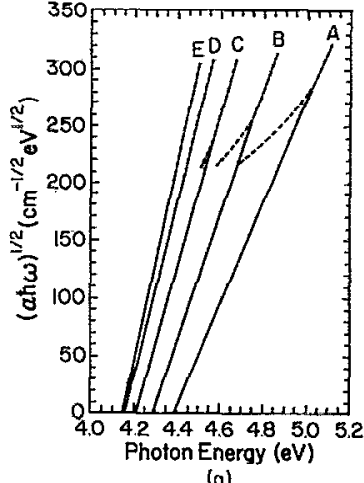

(a)

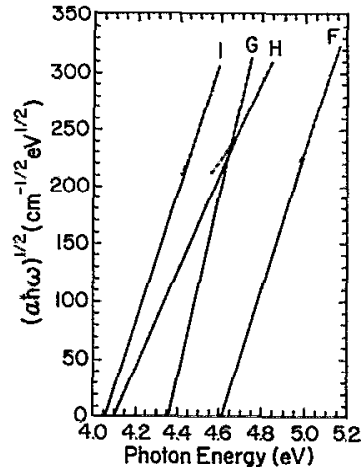

(b)
FIG. 3. $(\alpha \hbar \omega)^{1 / 2}$ against photon energy for glasses having various $\left[\mathrm{Cu}^{2+}\right]$ ratios with (a) $50 \%$, (b) $40 \%$, and $55 \%$ CuO batch composition.

In transition metal oxide glasses where small polaron conduction is supposed to occur, hopping is induced by the trapped electron absorbing a photon. Consequently, photon-induced hopping requires an energy of $\hbar \omega=4 W_{H}$, where $W_{H}$ is the activation energy for conduction. ${ }^{30}$ The optical energy gaps and the conduction activation energies for several binary phosphate glasses are listed in Table II. In general, the optical energy gap is approximately equal to or greater than $4 W_{H}$. Thus, from the reported activation energies for conduction in copper phosphate glasses, ${ }^{4,69,12,14,18,22}$ one would expect $E_{\text {opt }} \geqslant 4 \mathrm{eV}$. It should be noted that the values of the optical energy gap obtained in the present study all exceed $4 \mathrm{eV}$, while those reported by Hogarth and co-workers ${ }^{16-21}$ are less than $4 \mathrm{eV}$.

Figure 4 has plots of the $E_{\text {opt }}$ as a function of the $\left[\mathrm{Cu}^{2+}\right]$ ratio and shows that $E_{\text {opt }}$ increases linearly with a decreasing $\left[\mathrm{Cu}^{2+}\right]$ ratio for each batch composition. Also, one observes that $E_{\text {opt }}$ is enhanced with increasing $\mathrm{P}_{2} \mathrm{O}_{5}$ content in the glasses for a fixed $\left[\mathrm{Cu}^{2+}\right]$ ratio. Hence, $E_{\text {opt }}$ is a function of both glass composition and the $\left[\mathrm{Cu}^{2+}\right]$ ratio in the glass.

The variation of $E_{\text {opt }}$ with glass composition found here is consistent with previous observations that $E_{\text {opt }}$ increases as the $\mathrm{P}_{2} \mathrm{O}_{5}$ content in phosphate glasses is enhanced. ${ }^{26,27,38-43}$ This tendency has been explained by the decrease of nonbridging oxygen ions with increasing $\mathrm{P}_{2} \mathrm{O}_{5}$ content in the glasses. This behavior is observed, also, in silicate and borate glasses where the optical absorption edge shifts toward longer wavelength with increasing alkali content in the glasses. ${ }^{44}$ The dependence of $E_{\text {opt }}$ on the copper valence states ratio was studied in a copper calcium phosphate glasses containing varying iodine concentration. ${ }^{17}$ It was observed that $E_{\text {opt }}$ diminishes with increasing iodine concentration. Since iodine acts as an oxidizing agent, the glasses with larger concentration of iodine had larger $\left[\mathrm{Cu}^{2+}\right]$ ratios. Thus, it was found that $E_{\mathrm{opt}}$ decreases with an increasing $\left[\mathrm{Cu}^{2+}\right]$ ratio. Similar findings were made in vanadium phosphate glasses. ${ }^{26,27,38,39}$ Our present results for the behavior of $E_{\text {opt }}$ with changing $\left[\mathrm{Cu}^{2+}\right]$ ratio in the glass are in accordance with the results of the previous sludies quoted above. 
TABLE II. Comparison of optical energy gaps and conduction activation energies for binary phosphate glasses

\begin{tabular}{|c|c|c|c|}
\hline $\begin{array}{l}\text { Metal } \\
\text { oxide }\end{array}$ & $\begin{array}{c}\text { Nominal composition } \\
(\mathrm{mol} \%)\end{array}$ & $\begin{array}{l}\text { Optical energy gap } \\
\qquad(\mathrm{eV})\end{array}$ & $\begin{array}{c}\text { Activation energy } \\
(\mathrm{eV})\end{array}$ \\
\hline $\mathrm{V}_{2} \mathrm{O}_{5}$ & $\begin{array}{l}50 \\
60 \\
70 \\
80 \\
90\end{array}$ & $\begin{array}{l}2.43^{\mathrm{a}} \\
2.32^{\mathrm{a}} \\
2.21^{\mathrm{a}} \\
2.12^{\mathrm{a}} \\
2.02^{\mathrm{a}}\end{array}$ & $\begin{array}{c}0.42^{\mathrm{b}} \\
0.44^{\mathrm{c}}, 0.40^{\mathrm{d}} \\
0.38^{\mathrm{d}} \\
0.35^{\mathrm{d}} \\
0.32^{\mathrm{c}}\end{array}$ \\
\hline $\mathrm{MoO}_{3}$ & $\begin{array}{l}20 \\
30 \\
40 \\
50 \\
60 \\
70 \\
80\end{array}$ & $\begin{array}{l}3.10^{e} \\
3.00^{e} \\
2.88^{e} \\
2.67^{e} \\
2.58^{e} \\
2.44^{e} \\
2.34^{e}\end{array}$ & $\begin{array}{c}0.76^{\mathrm{f}} \\
0.74^{\mathrm{f}} \\
0.71^{\mathrm{f}} \\
0.67^{\mathrm{f}}, 0.59^{\mathrm{b}} \\
0.65^{\mathrm{f}} \\
0.62^{\mathrm{f}} \\
0.57^{\mathrm{f}}\end{array}$ \\
\hline $\mathrm{CdO}$ & $\begin{array}{l}20 \\
25 \\
30 \\
35 \\
40 \\
45 \\
50\end{array}$ & $\begin{array}{l}5.98^{\mathrm{g}} \\
5.88^{\mathrm{g}} \\
5.84^{\mathrm{g}} \\
5.64^{\mathrm{g}} \\
5.50^{\mathrm{g}} \\
5.28^{\mathrm{g}} \\
4.84^{\mathrm{g}}\end{array}$ & $\begin{array}{l}1.26^{\mathrm{g}} \\
1.22^{\mathrm{g}} \\
1.21^{\mathrm{g}} \\
1.19^{\mathrm{g}} \\
1.17^{\mathrm{B}} \\
1.10^{\mathrm{g}} \\
0.99^{\mathrm{g}}\end{array}$ \\
\hline $\mathrm{Pr}_{6} \mathrm{O}_{11}$ & $5-12.5$ & $5.00-5.04^{\mathrm{h}}$ & $1.09-1.13^{\mathrm{i}}$ \\
\hline $\mathrm{CuO}$ & $\begin{array}{l}35 \\
40 \\
50 \\
55\end{array}$ & $\begin{array}{c}3.62^{j} \\
4.37-4.62^{\circ} \\
3.42^{\mathrm{k}}, 3.24^{\mathrm{l}} \\
4.14-4.39^{\circ} \\
4.06-4.06^{\circ}\end{array}$ & $\begin{array}{c}1.11^{\mathrm{m}} \\
1.05-1.20^{\mathrm{n}} \\
1.03^{\mathrm{b}}, 1.00^{\mathrm{n}} \\
1.05^{\mathrm{k}}\end{array}$ \\
\hline 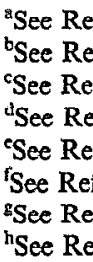 & $\begin{array}{l}\text { erence } 40 . \\
\text { erence } 4 . \\
\text { erence } 55 . \\
\text { erence } 6 . \\
\text { erence } 44 . \\
\text { erence } 54 . \\
\text { eerences } 40,53 \text {. } \\
\text { ference } 45 .\end{array}$ & \multicolumn{2}{|l|}{$\begin{array}{l}\text { iSee Reference } 46 . \\
\text { jSee Reference } 20 . \\
\text { 'See Reference } 18 . \\
{ }^{\mathrm{I} S e e} \text { Reference } 19 . \\
{ }^{\mathrm{m}} \text { See Reference } 14 . \\
\text { "See Reference } 9 . \\
\text { "oresent study. }\end{array}$} \\
\hline
\end{tabular}

In summary, we observe that $E_{\text {opt }}$ depends both upon valence states ratio of copper and glass composition. This finding is in contradiction with the hypothesis of Hogarth and co-workers, who interpret the decrease of $E_{\mathrm{opt}}$ with

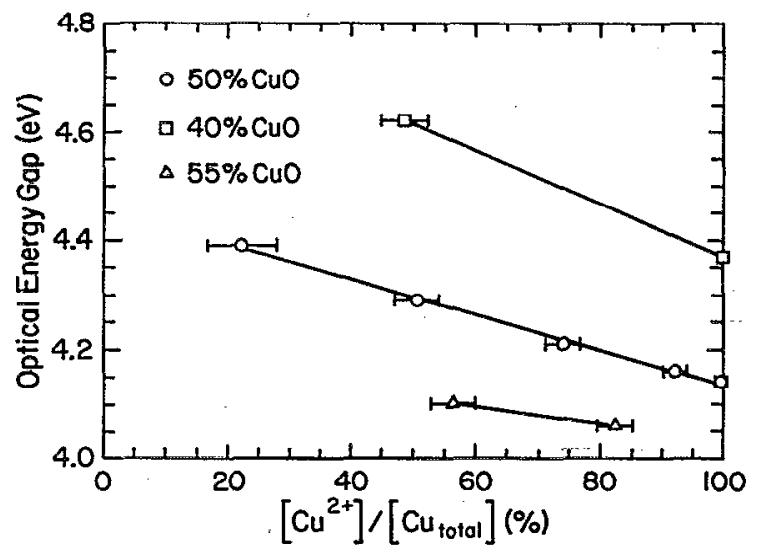

FIG. 4. Variation of optical energy gap as a function of $\left[\mathrm{Cu}^{2+}\right]$ ratio.

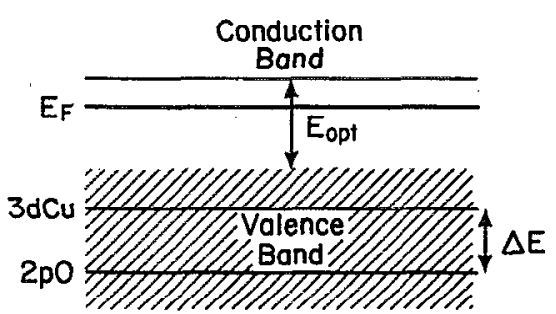

FIG. 5. Suggested energy band representation for copper phosphate glasses. The separation $(\Delta E)$ between $3 d \mathrm{Cu}$ and $2 p \mathrm{O}$ states determines the edge of the valence band, which is formed by hybridization of two states.

increasing $\mathrm{CuO}$ content solely in terms of the reduction of the $\left[\mathrm{Cu}^{2+}\right]$ ratio in the glass.

\section{B. Energy band structure}

Even though the origin of the optical energy gap in these glasses is not well established, it is probable due to charge transfer excitation of electrons. The energy gap of vanadium phosphate was postulated to be due to the transition of oxygen $2 p$-like electrons into the conduction band near the vanadium $3 d$ band. ${ }^{26,27}$ The electronic structures of the glassy and crystalline states may not be significantly different due to their nearly identical local order. Therefore, it is plausible to describe the optical energy gap of the glass from knowledge of the electronic structure of the corresponding crystalline compound. Although energy bands and electronic structures of crystalline copper phosphates are not available, those of crystalline $\mathrm{CuO}$ and $\mathrm{Cu}_{2} \mathrm{O}$ are known from calculations ${ }^{47,48}$ and spectroscopy. ${ }^{49}$ The smaller energy band gap of crystalline $\mathrm{CuO}(\mathrm{Eg}=0.3$ $\mathrm{eV})$ compared to that of crystalline $\mathrm{Cu}_{2} \mathrm{O}(\mathrm{Eg}=2.17 \mathrm{eV})$ is in accordance with the decrease of $E_{\text {opt }}$ with an increasing $\left[\mathrm{Cu}^{2+}\right]$ ratio in the glass. Recently, there have been numerous studies of the electronic and energy band structures of high $T_{c}$ superconductung crystalline copper oxide compounds. ${ }^{47,50,51}$ It has been found that the upper valence band edge is mainly $2 p$ oxygen states for dielectric compounds $\left(\mathrm{Li}_{2} \mathrm{CuO}_{2}, \mathrm{KCuO}_{2}, \mathrm{NaCuO}_{2}\right)$ and is a hybridized $3 d$ copper and $2 p$ oxygen state for wide gap semiconductors $\left(\mathrm{Cu}_{4} \mathrm{O}_{3}, \mathrm{SrCuO}_{2}, \mathrm{Sr}_{2} \mathrm{CuO}_{3}, \mathrm{LaCuO}_{2}\right){ }^{47}$ Thus, it is reasonable to postulate that the optical energy gap of copper phosphate glass is due to the excitation of electrons from the hybridized $3 d$ copper and $2 p$ oxygen states to the conduction band near the Fermi energy. The optical energy gap depends on the energy level of the upper valence band edge, which is determined by the separation of $3 d$ copper and $2 p$ oxygen states, as illustrated in Fig. 5. For small separation between these states, hybridization of $3 d$ copper and $2 p$ oxygen states can occur easily, as has been found in metallic or semiconducting copper oxides. ${ }^{51} \mathrm{Hy}-$ bridization broadens the valence band and moves the upper valence band edge to higher energy, resulting in a smaller energy band gap. Therefore, it may be plausible that the separation between $3 d$ copper and $2 p$ oxygen states, which depends on the chemical bonding characteristics in the glasses, determines the optical energy gap. 
The variation of $E_{\text {opt }}$ with glass composition can be explained as follows. The higher concentration of charged nonbridging oxygen ions with reducing $\mathrm{P}_{2} \mathrm{O}_{5}$ content causes an increase in $2 p$ oxygen energy levels. This rise of $2 p$ oxygen levels shorten the separation between $3 d$ copper and $2 p$ oxygen states, broadening the valence band, and thus diminishing $E_{\text {opt }}{ }^{26}$

The variation of $E_{\mathrm{opt}}$ with changes in the $\left[\mathrm{Cu}^{2+}\right]$ ratio can be explained in the following manner. A theoretical study of the energy bands of transition metal oxide compounds based on an ionic model ${ }^{52}$ has reported that the separation between transition metal $3 d$ and oxygen $2 p$ states is very sensitive to oxygen charge. As the ionicity of oxygen diminishes in the copper oxide compounds, the $3 d$ copper state decreases and the $2 p$ oxygen state rises so that the separation between two states reduces, as observed in crystalline copper oxide compounds. ${ }^{47}$ Thus, the higher covalent character of the $\mathrm{Cu}^{2+}-\mathrm{O}$ bonding compared to the $\mathrm{Cu}^{1+}-\mathrm{O}$ bonding in copper oxide compounds ${ }^{47}$ decreases the separation between $3 d$ copper and $2 p$ oxygen states. This feature is illustrated by smaller value of the energy gap in crystalline $\mathrm{CuO}$ than in crystalline $\mathrm{Cu}_{2} \mathrm{O} .{ }^{47-49}$ Hence, for higher $\left[\mathrm{Cu}^{2+}\right]$ ratios in the glasses, the optical energy gap is reduced, as we have observed, since the separation between $3 d$ copper and $2 p$ oxygen becomes smaller. This is accordance with the theoretical predictions that increased covalent character of the bonds causes a decrease in the absorption edge energy. ${ }^{44}$ In addition, one should note that $\mathrm{Cu}^{1+}$ and $\mathrm{Cu}^{2+}$ exist in different coordinations with respect to oxygens in phosphate glasses, ${ }^{36}$ and such differences, also, can cause a change in the nature of the oxygen bonds, which may influence the optical energy gap.

\section{Optical absorption tail}

The optical absorption edge of many amorphous semiconductors is characterized by the tail of the absorption edge where the absorption coefficient, $\alpha(\omega)$, rises exponentially with photon energy, $\hbar \omega,{ }^{28-30,37}$

$$
\alpha(\omega)=\alpha_{0} \exp \left(\frac{\hbar \omega}{\Delta E}\right)
$$

where $\alpha_{0}$ is constant and $\Delta E$ is called the Urbach energy. The nature of the exponential dependence of the absorption coefficient on photon energy in amorphous semiconductors is obscure. The exponential tail of the absorption edge could be postulated as arising from transitions between localized states whose density is exponentially dependent on energy ${ }^{37}$ However, this explanation has been disputed, ${ }^{28}$ and it seems more likely to be due to a random internal electric field, created either by the lack of longrange order or by the presence of defects, ${ }^{56}$ or to the electric field of an exciton state. ${ }^{57}$ In any case, $\Delta E$ represents the width of the band tails of the localized states. Figure 6 shows the variation of $\ln (\alpha)$ with photon energy for all glasses in the range of $\alpha(\omega)<10^{4} \mathrm{~cm}^{-1}$. A linear plot is obtained for a certain region of absorption coefficient, which indicates Urbach's rule is followed in the region.

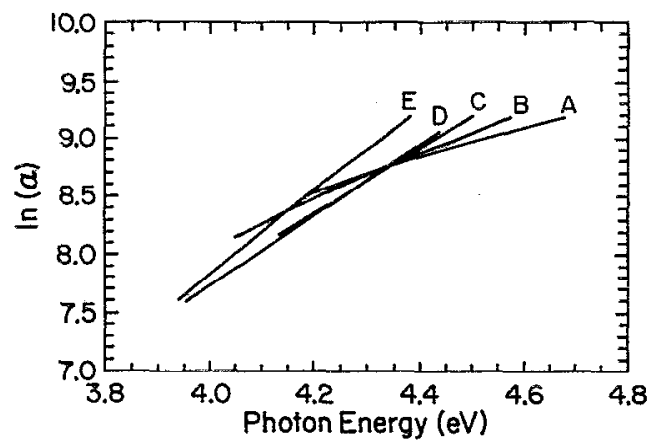

(a)

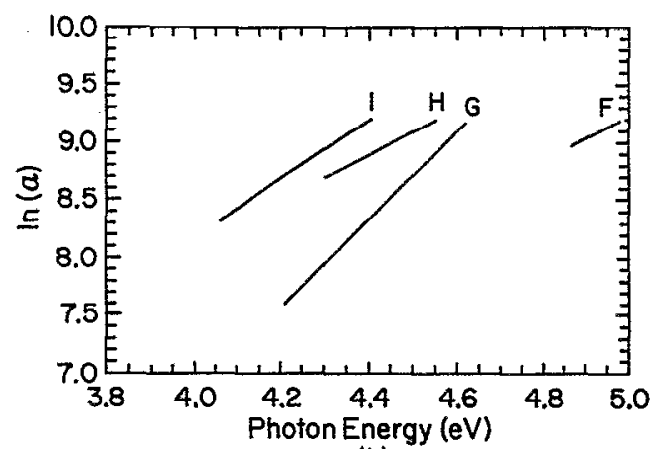

(b)

FIG. 6. In $(\alpha)$ against photon energy for glasses having various $\left[\mathrm{Cu}^{2+}\right]$ ratios with (a) $50 \%$, (b) $40 \%$, and $55 \%$ CuO batch composition.

One can note that the linear range is shortened as the $\left[\mathrm{Cu}^{2+}\right]$ ratio of the glasses increases. The values of $\Delta E$ in Eq. (2) are calculated from the slopes of the linear plots and are given in Table $I$. The variation of $\Delta E$ as a function of $\left[\mathrm{Cu}^{2+}\right]$ ratio is presented in Fig. $7 . \Delta E$ rises from 0.26 to $0.82 \mathrm{eV}$ exponentially with a decreasing $\left[\mathrm{Cu}^{2+}\right]$ ratio but is independent of the batch composition. The $\Delta E$ 's obtained for the copper phosphate glasses are much larger than the values for other oxide glasses. ${ }^{38,42,43}$ Thus, it is doubtful whether the tail of the absorption edge is caused only by the fundamental absorption edge. A careful analysis of the

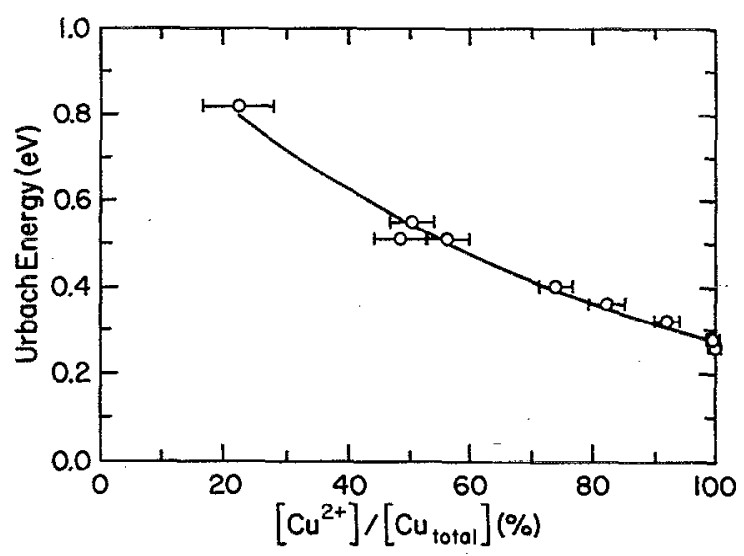

FIG. 7. Variation of Urbach energy as a function of $\left[\mathrm{Cu}^{2+}\right]$ ratio. 


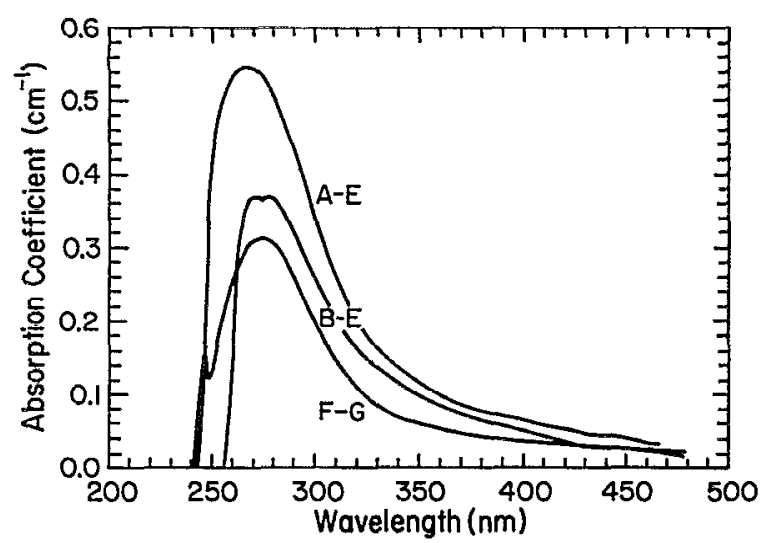

FIG. 8. Optical absorption bands obtained by subtracting the spectra of oxidized glass ( $E$ and $G$ ) from the spectra of reduced glass $(A, B$, and $F$ ).

absorption edge of vanadate glasses suggested that a broad absorption band at around $2.3 \mathrm{eV}$, which is characteristic of $\mathrm{V}^{4+}$ in a tetragonally distorted environment, overlaps the fundamental absorption edge. ${ }^{27,39}$ Also, the absorption bands of iron ions in crystal fields were observed near the absorption edge of iron phosphate glass. ${ }^{30}$ For crystalline solids $^{58}$ as well as for glasses containing copper, ${ }^{31-35}$ it has been found that absorption bands of $\mathrm{Cu}^{1+}$ are produced at 200-300 nm. For example, it has been reported that the absorption bands in calcium metaphosphate glass are due to the trigonally distorted octahedral coordination of $\mathrm{Cu}^{1+} \cdot{ }^{31}$ Thus, it is reasonable to expect that the broad absorption band of $\mathrm{Cu}^{1+}$ overlaps the fundamental absorption edge and the tail of absorption edge is governed mostly by the absorption band of $\mathrm{Cu}^{1+}$. This could explain why $\Delta E$ is dependent only on the $\left[\mathrm{Cu}^{2+}\right]$ ratio and not on the batch composition. The linear region of the plot in Fig. 7 in which Urbach's rule is obeyed is shortened as the $\left[\mathrm{Cu}^{2+}\right]$ ratio decreases since the absorption band of $\mathrm{Cu}^{1+}$ makes a larger contribution. The absorption edges of the $E$ and $G$ glasses, which are nearly devoid of $\mathrm{Cu}^{1+}$, are intrinsic absorption edges without the overlapping absorption band of $\mathrm{Cu}^{1+}$. When the absorption coefficients of the oxidized glasses are subtracted from those of the reduced glasses of the same batch composition, then broad absorption bands centered at about $270 \mathrm{~nm}$ are obtained as illustrated in Fig. 8. The height of the absorption bands seems to be a function of the concentration of $\mathrm{Cu}^{1+}$ in the glasses $(A>B$ $>F$ ). Thus, these absorption bands are the crystal field absorption bands of $\mathrm{Cu}^{1+}$ in a trigonally distorted octahedral environment. The wide distribution of local electric field intensities in the glasses is responsible for the breadth of these absorption bands, which in turn produce large $\Delta E$ values for these glasses.

\section{CONCLUSION}

The optical energy gap, $E_{\mathrm{opt}}$, of copper phosphate glass is a function of both glass composition and $\left[\mathrm{Cu}^{2+}\right]$ ratio present in the glass. $E_{\text {opt }}$ increases as the $\mathrm{CuO}$ content for fixed $\left[\mathrm{Cu}^{2+}\right]$ ratio and the $\left[\mathrm{Cu}^{2+}\right]$ ratio for fixed glass com- position are reduced. Electron excitation from hybridized $3 d$ copper and $2 p$ oxygen states to the conduction band near the Fermi energy is suggested to be the factor controlling the observed variation of $E_{\text {opt }}$ with $\mathrm{CuO}$ content and $\left[\mathrm{Cu}^{2+}\right]$ ratio in the glass. Optical absorption bands of $\mathrm{Cu}^{1+}$ in its crystal field overlap the tail of the intrinsic absorption edge and broaden it. Therefore, the Urbach energy, $\Delta E$, is determined largely by the $\left[\mathrm{Cu}^{2+}\right]$ ratio in the glass rather than by the glass composition.

\section{ACKNOWLEDGMENTS}

This work has been supported by the Jet Propulsion Laboratory and the Division of Microgravity Science and Applications of the National Aeronautics and Space Administration. The authors would like to thank the Advanced Technology Center of Donnelly Corporation in Tucson, AZ, for permitting our use of their Optical Absorption Spectrophotometer.

'J. D. Mackenzie, in Modern Aspects of the Vitreous State, edited by J. D. Mackenzie (Butterworths, London, 1964), Vol. 3, p. 126.

${ }^{2}$ N. F. Mott, J. Non-Cryst. Solids 1, 1 (1968).

${ }^{3}$ I. G. Austin and N. F. Moll, Adv. Phys. 18, 41 (1969).

${ }^{4}$ M. Sayer and A. Mansingh, Phys. Rev. B 6, 4629 (1972).

${ }^{5}$ I. G. Austin and E. S. Garbett, in Electronic and Structural Properties of Amorphous Semiconductors, edited by P. G. Le Comber and J. Mort (Academic, London, 1973), p. 393.

${ }^{6}$ I. G. Austin and M. Sayer, J. Phys. C 7, 905 (1974).

${ }^{7}$ L. Murawski, C. H. Chung, and J. D. Mackenzie, J. Non-Cryst. Solids 32, 91 (1979); Rev. Chim. Min. 16, 308 (1979)

${ }^{8} \mathrm{~J}$. O. Isard, J. Non-Cryst Solids 42, 371 (1980).

${ }^{9}$ T. Tsuchiya and T. Moriya, Cent. Glass. Ceram. Res. Inst. Bull. 22, 55 (1975).

${ }^{10}$ G. R. Moridi and C. A. Hogarth, in The Physics of Non-Crystalline Solids, edited by G. H. Frischat (Trans. Tech., 1977), p. 254.

${ }^{11}$ C. A. Hogarth and A. I. Popov, Int. J. Electron. 54, 171 (1983).

${ }^{12}$ A. Duran, J. R. Jurado, and M. F. Navarro, J. Non-Cryst. Solids 79, 333 (1986), J. Non-Cryst. Solids 79, 353 (1986).

${ }^{13}$ A. Duran and J. R. Jurado, J. Mater. Sci. Lett. 5, 925 (1986).

${ }^{14}$ R. Harani and C. A. Hogarth, J. Mater. Sci. 21, 3509 (1986).

${ }^{15}$ M. A. Hassan, C. A. Hogarth, and G. R. Moridi, Phys. Status Solidi A 101, 537 (1987).

${ }^{16} \mathrm{G}$. R. Moridi, and C. A. Hogarth, in Proceedings of the 7th International Conference on Amorphous Liquid Semiconductors, edited by W. E. Spear (U. of Edinburgh Press, 1977), p. 688.

${ }^{17}$ C. A. Hogarth, and A. A. Novikov, J. Phys. D 16, 675 (1983).

${ }^{18}$ E. E. Khawaja, M. N. Khan, A. A. Kutub, and C. A. Hogarth, Int. J. Electron. 58, 471 (1985).

${ }^{19}$ A. A. Kutub, A. E. Mohamed-Osman, and C. A. Hogarth, J. Mater. Sci. 21, 3517 (1986).

${ }^{20}$ S. P. Edirisinghe and C. A. Hogarth, J. Mater. Sci. Lett. 8, 789 (1989).

${ }^{21}$ J. M. Arzeian, and C. A. Hogarth, J. Mater. Sci. 26, 5353 (1991).

${ }^{22}$ C. F. Drake, I. F. Scanlan, and A. Engel, Phys. Status Solidi 32, 193 (1969).

${ }^{23}$ G. R. Moridi and C. A. Hogarth, Int. J. Electron. 44, 297 (1978).

${ }^{24} \mathrm{~J}$. Wong and C. A. Angel, Glass Structure by Spectroscopy (Marcel Dekker, New York, 1976), p. 149.

${ }^{25}$ F. A. Cotton, G. Wilkinson, and P. L. Gaus, Basic Inorganic Chemistry, 2nd ed. (Wiley, New York, 1987), p. 466.

${ }^{26}$ G. W. Anderson and W. D. Compton, J. Chem. Phys. 52, 6166 (1970).

${ }^{27}$ G. W. Anderson, J. Appl. Phys. 44, 406 (1973).

${ }^{28}$ E. A. Davis and N. F. Mott, Philos. Mag. 22, 903 (1970).

${ }^{29}$ N. F. Mott and E. A. Davis, Electronic Processes in Non-Crystalline Materials (Clarendon, Oxford, 1971), p. 237.

${ }^{30}$ I. G. Austin, M. Sayer, and R. S. Sussmann, in Proceedings of the 5th International Conference on Amorphous Liquid Semiconductors, Garmisch (Taylor and Francis, London, 1974), Vol. II, p. 1343.

${ }^{31}$ R. Dbnath, J. Chaudhury, and S. C. Bera, Phys. Status Solidi B 157, 723 (1990). 
${ }^{32}$ S. Shionoya and E. Nakazawa, Appl. Phys. Lett. 6, 118 (1965).

${ }^{33}$ S. Parke and R. S. Webb, Phys. Chem. Glasses 13, 157 (1972).

${ }^{34}$ L. Huimin and G. Fuxi, J. Non-Cryst. Solids 80, 447 (1986).

${ }^{35}$ R. Debnath, J. Lumin. 43, 375 (1989).

${ }^{36}$ B. S. Bae and M. C. Weinberg, J. Am. Ceram. Soc. 74, 3039 (1991).

${ }^{37} \mathrm{~J}$. Tauc, in Optical Properties of Solids, edited by F. Abeles (NorthHolland, Amsterdam, 1970), p. 277.

${ }^{38}$ C. A. Hogarth and A. A. Hosseini, J. Mater. Sci. 18, 2697 (1983).

${ }^{39}$ F. P. Koffyberg and N. J. Koziol, J. Appl. Phys. 47, 4701 (1976).

${ }^{40}$ C. A. Hogarth and M. A. Ghauri, J. Mater. Sci. 14, 1641 (1979).

${ }^{41}$ R. Harani and C. A. Hogarth, J. Mater. Sci. Lett. 4, 399 (1985).

${ }^{42}$ M. K. Hekmat-Shoar, C. A. Hogarth, and G. R. Moridi, J. Mater. Sci. 26, 904 (1991).

${ }^{43}$ S. K. J. Al-Ani and A. A. Higazy, J. Mater. Sci. 26, 3670 (1991).

${ }^{44}$ B. D. McSwain, N. F. Borrelli, and G. Su, Phys. Chem. Glasses 4, 1 (1963).

${ }^{45}$ M. M. Ahmed, R. Harani, and C. A. Hogarth, J. Mater. Sci. Lett. 3, 1055 (1984).

${ }^{46}$ R. Harani and C. A. Hogarth, J. Mater. Sci. Lett. 5, 492 (1986).
${ }^{47}$ R. A. Evarestov, and V. A. Veryazov, Phys. Status Solidi B 157, 281 (1990); Phys. Status Solidi B 158, 201 (1990).

${ }^{48}$ P. Marksteiner, P. Blaha, and K. Schwarz, Z. Phys. B 64, 119 (1986).

${ }^{49}$ C. Benndorf, H. Caus, B. Egert, H. Seidel, and F. Thieme, J. Electron Spectrosc. Relat. Phenom. 19, 77 (1980).

${ }^{50}$ L. F. Mattheiss, Phys. Rev. Lett. 58, 1028 (1987)

${ }^{51}$ K. T. Park, K. Terakura, T. Oguchi, A. Yanase, and M. Ikeda, J. Phys. Soc. Jpn. 57, 3445 (1988).

${ }^{52}$ A. H. Kahn and A. J. Leyendecker, Phys. Rev. 135, A1321 (1964).

${ }^{53}$ M. A. Ghauri, W. H. Bokhari, and F. M. Nazar, Int. J. Electron. 51, 201 (1981).

${ }^{54}$ M. H. Hekmat-Shoar, C. A. Hogarth, and G. R. Moridi, J. Mater. Sci. 20, 889 (1985).

${ }^{55}$ G. S. Linsley, A. E. Owen, and F. M. Hayatee, J. Non-Cryst. Solids 4, 208 (1970).

${ }^{56}$ D. Redfield, Phys. Rev. 140, A 2056 (1965).

${ }^{57}$ J. D. Dow and D. Redfield, Phys. Rev. B 1, 3358 (1970); Phys. Rev. B 5, 594 (1972).

${ }^{58}$ M. Bertolaccini, P. Gagliardelli, and G. Padovini, J. Lumin. 14, 281 (1976). 